\title{
PEMROGRAMAN DAN FLOW DESIGN UNTUK RANGKAIAN LAMPU LIGHT EMITTING DIODE (LED) BERBASIS RASPBERRY PI 3B MENGGUNAKAN NODE-RED PADA RANCANG BANGUN GREENHOUSE AUTOMATION SYSTEM (GAS)
}

\author{
Muhammad Azmi Rafly \\ Azmiiraflyy23@gmail.com \\ Jurusan Teknik Informatika dan Komputer \\ Politeknik Negeri Jakarta \\ Depok, Indonesia
}

\begin{abstract}
Abstraksi
Iklim yang cenderung sulit untuk diprediksi secara langsung membuat para petani sulit memenuhi kuantitas, kualitas dan kontinuitas produksi sehingga belum terealisasi dengan baik atau optimal. Greenhouse merupakan sebuah bangunan kontruksi yang berfungsi untuk menghindari atau memanipulasi kondisi lingkungan agar tercipta kondisi lingkungan yang dikehendaki dalam pemeliharaan tanaman. Dengan memanfaatkan teknologi Internet of Things (IoT) untuk membantu proses perawatan pada tanaman di dalam greenhouse, padahal dengan menggunakan Internet of Things dapat mempermudah petani dalam hal monitoring dan controlling. Monitoring yang dimaksudkan antara lain keadaan udara, air, dan tanah yang ada di dalam ruangan hingga mengontrol nyala lampu UV untuk menggantikan matahari.
\end{abstract}

Kata kunci : Greenhouse, Internet of Things, IoT, Controlling

\section{Pendahuluan}

Perancangan sebuah sisem IoT membutuhkan Programming didalamnya. Programming tersebut berfungsi sebagai penghubung dari aplikasi yang digunakan oleh end-user untuk melakukan fungsi-fungsi terhadap alat pada IoT yang terinstall. Programming untuk IoT dapat menggunakan berbagai bahasa pemrograman sesuai dengan alat dan kebutuhan yang akan digunakan sebagai inti dari alat IoT tersebut. Programmer membuat program agar fungsifungsi di aplikasi dapat berfungsi, berkomunikasi dengan baik, dan juga mengontrol alat IoT sesuai dengan apa yang diinginkan.

Programmer dituntut untuk dapat mengerti, memahami dan menyesuaikan bahasa apa yang digunakan sesuai dengan alat dan kebutuhan. Banyaknya alat, bedanya value tiap penggerak alat, dan logika yang digunakan sebuah alat membuat Programmer harus memilih bahasa pemrograman yang dapat masuk dan di proses sesuai semua alat yang akan terhubung seperti alat penggerak Iot, mikroprosessor yang digunakan, antarmuka untuk end-user, database untuk menyimpan value dari alat, dan fungsi logis untuk menghubungkan semuanya.

Dari permasalahan diatas dapat disimpulkan bahwa dibutuhkan sebuah bahasa program yang dapat menghubungkan antara alat penggerak Iot, mikroprosessor yang digunakan, antarmuka untuk end-user, database untuk menyimpan value dari alat, dan fungsi logis secara efektif dan efisien. Pemrograman fungsi dlakukan dengan menggunakan Node-Red berbasis Javascript yang akan diinstall pada Raspberry Pi.

\section{Tinjauan Pustaka}

Greenhouse Automation System (GAS) merupakan sebuah sistem tertanam yang terintegrasi dengan android dan layanan web yang dibangun untuk memantau dan mengontrol alat yang berada di greenhouse. GAS dirancang untuk solusi monitoring dan otomasi perkebunan dalam ruangan.

1. Node.JS 
Node.js adalah perangkat lunak yang didesain untuk mengembangkan aplikasi berbasis web dan ditulis dalam sintaks bahasa pemrograman JavaScript. Node.js ada untuk melengkapi peran JavaScript sehingga bisa juga berlaku sebagai bahasa pemrograman yang berjalan di sisi server, seperti halnya PHP, Ruby, Perl, dan sebagainya. Node.js dapat berjalan di sistem operasi Windows, Mac OS X dan Linux tanpa perlu ada perubahan kode program. Node.js memiliki pustaka server HTTP sendiri sehingga memungkinkan untuk menjalankan server web tanpa menggunakan program server web seperti Apache atau Nginx.

\section{Node-Red}

Node-RED adalah sebuah tool berbasis browser untuk membuat aplikasi Internet of Things (IoT) yang mana lingkungan pemrograman visualnya mempermudah penggunanya untuk membuat aplikasi sebagai "flow". Lanskap bahasa pemrograman sangatlah luas dan meliput berbagai jenis gaya dan paradigma pemrograman. Bahasa imperatif berorientasi objek saat ini menguasai dunia pemrograman, namun begitu sebetulnya ada alternatif untuk pengembangan atau produksi software dan juga untuk membuat prototipe ide dengan cepat.

Node-RED mengambil jalur alternatif tersebut untuk pengembangan software. Pertama, ia adalah bahasa pemrograman visual. Daripada membuat aplikasi sebagai barisan kodingan, Node-RED fokus ke program sebagai flow. Flow ini terbentuk dari node-node yang saling berhubungan di mana tiap node melakukan tugas tertentu. Walaupun Node-RED didesain untuk Internet of Things (IoT), ia juga dapat digunakan untuk keperluan umum dan untuk berbagai macam jenis aplikasi.

Node-RED sebetulnya adalah tool baru yang berasal dari IBM dan dirilis sebagai open source pada tahun 2013. Fokus Node-RED adalah sebagai tool pemrograman IoT untuk keperluan umum, namun ia telah berkembang penggunaannya karena kesederhanaannya dan kekuatannya untuk berbagai jenis aplikasi.

\section{Rangkaian}

Komponen sebuah rangkaian listrik atau rangkaian elektronik dapat dihubungkan dengan berbagai cara. Dua tipe paling sederhana adalah rangkaian seri dan parallel. Rangkaian yang disusun secara sejajar disebut rangkaian seri, sedangkan rangkaian yang disusun secara berderet disebut rangkaian paralel. Komponen yang tersusun seri akan terhubung melalui satu jalur, sehingga aliran arus listrik akan mengalir ke semua komponen. Pada rangkaian paralel, tegangan yang melewati tiap komponen adalah sama, dan total arus adalah jumlahan arus yang melewati tiap komponen.

Sebuah rangkaian sederhana yang terdiri dari 4 lampu dan satu baterai $6 \mathrm{~V}$. Jika keempat lampu terhubung seri, maka arus yang melewati tiap lampu sama dan voltage drop turun $1.5 \mathrm{~V}$ setiap lampu, yang mungkin tidak cukup untuk menyalakan semua lampu. Jika keempat lampu terhubung paralel, arus yang melalui tiap lampu akan digabungkan, sedangkan voltage drop turun melalui tiap lampu dan semuanya bisa menyala.

Rangkaian lampu pada GAS in menggunakan rangkaian listrik parallel, yaitu suatu rangkaian listrik, di mana semua input komponen berasal dari sumber yang sama. Semua komponen satu sama lain tersusun paralel. Hal inilah yang menyebabkan susunan paralel dalam rangkaian listrik menghabiskan biaya yang lebih banyak (kabel penghubung yang diperlukan lebih banyak). Selain kelemahan tersebut, susunan paralel memiliki kelebihan tertentu dibandingkan susunan seri. Adapun kelebihannya adalah jika salah satu komponen dicabut atau rusak, maka komponen yang lain tetap berfungsi sebagaimana mestinya. 


\section{Metode Penelitian}

Perancangan Alat ini menggunakan metode System Development Life Cycle (SDLC). Adapun tahapantahapan metode SDLC adalah sebagai berikut:

\section{Tahap Perencanaan (System Planning)}

Pada tahap ini dilakukan pengindentifikasian masalah-masalah yang dapat diselesaikan oleh aplikasi dan sistem yang akan dibangun atau dikembangkan, dan untuk menentukan teknologi yang tepat untuk aplikasi dan sistem yang akan dibangun.

\section{Tahap Analisis (System Analisis)}

Pada tahap ini dilakukan analisa dan pendefinisan kebutuhan sistem dan aplikasi yang akan dibangun serta membuat batasan sistem dan aplikasi tersebut.

\section{Tahap Perancangan (System Design)}

Dalam tahap ini dilakukan analisa interaksi obyek dan fungsi pada aplikasi dan sistem yang akan dibangun, analisa dan pembuatan skema database, serta perancangan user interface.

4. Tahap Implementasi (System Implementation)

Pada tahap ini pengimplementasian rancangan yang sudah dibuat pada tahap sebelumnya dan pengujian terhadap aplikasi dan sistem yang sudah dibangun dilakukan.

\section{Tahap Pemeliharaan (System Maintenance)}

Tahap ini dilakukan oleh admin yang ditunjuk untuk menjaga sistem dan aplikasi yang sudah dibangun agar tetap mampu beroperasi secara benar melalui kemampuan sistem dan aplikasi yang akan dibangun dalam mengadaptasikan diri sesuai dengan kebutuhan.

\section{Arsitektur}

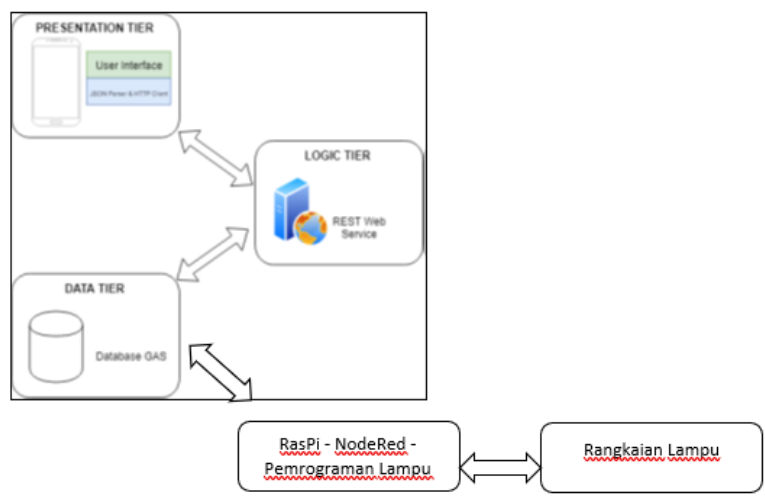

Pemrograman NodeRed untuk rangkaian lampu dilakukan didalam Raspberry Pi yang sudah terinstall NodeRed, yang nantinya akan berisi perintah perintah untuk menyalakan rangkaian lampu dan juga mengisi value status lampu kedalam database GAS. Pemrograman berbasis NodeRed ini diakses melalui remote dari client lain yang berada pada satu jaringan dengan Raspberry $\mathrm{Pi}$ melalui browser, dan langsung membuat Flow didalamnya beserta fungsinya.

\section{Diagram Flow Node-RED}

Flow ini dibuat langsung didalam NodeRed.
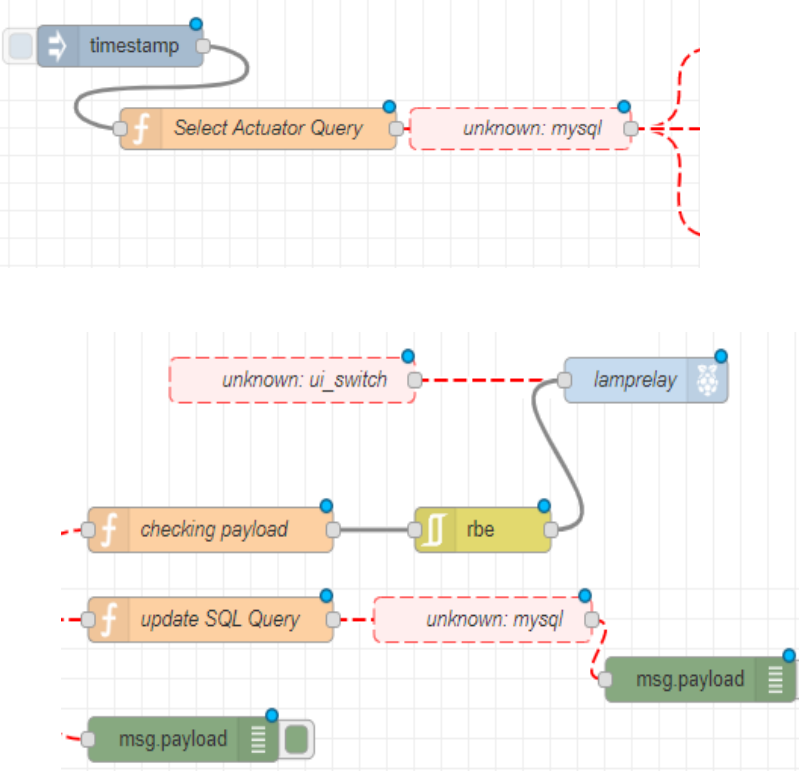

Flow dimulai dari Timestamp, yang digunakan untuk memberikan nilai input 
secara manual langsung dari dalam NodeRed. Dilanjut dengan fungsi yang berisi memilih query untuk actuator yang digunakan karena disini menggunakan relay. Kemudian mengkoneksikan flow dengan database MySQL. Ketika timestamp di klik, maka akan melakukan 3 aksi, yaitu check payload untuk aksi ke relay yang digunakan, update SQL query untuk memberi nilai input dari status yang sudah di update juga memberikan keluaran msgPayload untuk melakukan debugging, dan yang terakhir melakukan aksi msgPayload untuk cek apakah aksi sudah berhasil dilakukan dan juga ditampilkan untuk debugging.

\section{HASIL DAN PENGUJIAN}

Pemrograman Nodered lampu yang digunakan untuk aplikasi android GAS dikonfigurasi dengan menggunakan NodeRed dan menggunakan bahasa Javascript. Implementasi arsitektur NodeRed memberikan keuntungan dalam pembangunan aplikasi android GAS karena pemrograman yang dihasilkan lebih sederhana dikarenakan flow yang mudah. Penggunaan pemrograman Nodered untuk menyalakan dan mematikan rangkaian lampu menghasilkan fungsi sesuai yang diharapkan dengan adanya respon dari rangkaian lampu yang menyala dan mati.

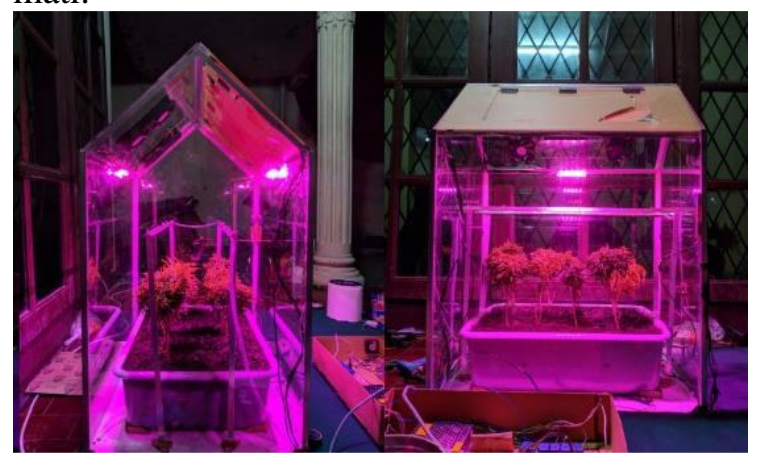

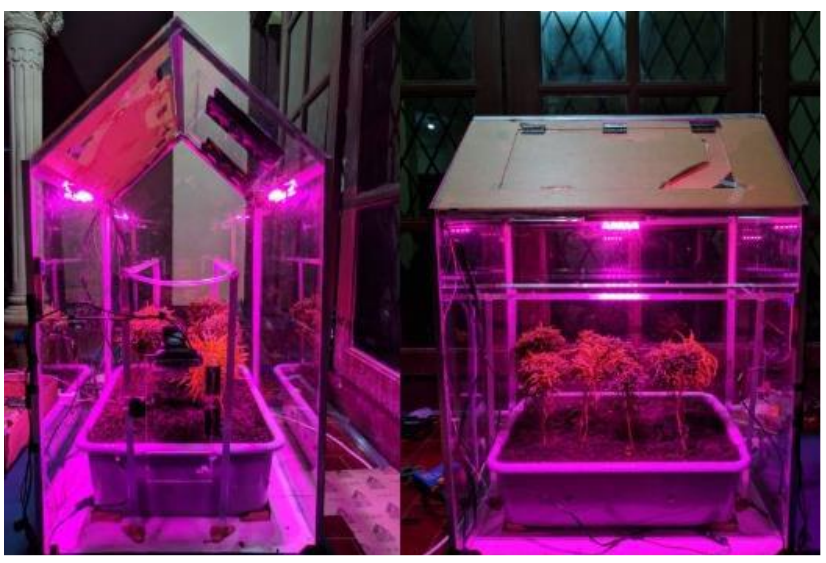

\begin{tabular}{|l|c|c|c|c|c|l|}
\hline \multirow{2}{*}{$\begin{array}{l}\text { Proses } \\
\text { yang } \\
\text { dilakukan }\end{array}$} & \multicolumn{4}{|c|}{$\begin{array}{l}\text { Waktu yang diperlukan } \\
\text { (detik) tiap percobaan }\end{array}$} & \multicolumn{2}{l}{$\begin{array}{l}\text { Rata- } \\
\text { rata } \\
\text { (detik) }\end{array}$} \\
\cline { 2 - 7 } & $\mathbf{1}$ & $\mathbf{2}$ & $\mathbf{3}$ & $\mathbf{4}$ & $\mathbf{5}$ & \\
\hline $\begin{array}{l}\text { Menyalakan } \\
\text { lampu dari } \\
\text { sistem GAS }\end{array}$ & 0,98 & 0,88 & 1,12 & 0,90 & 1 & 0.98 \\
\hline
\end{tabular}

\section{KESIMPULAN}

Pemrograman melalui NodeRed untuk pengontrolan rangkaian lampu dapat dilakukan dengan baik dan respon yang dihasilkan sesuai dengan harapan awal. Pemrograman melalui NodeRed ini berbasis bahasa Javascript yang sudah dibuatkan UI untuk mempermudah melakukan pemrograman dengan fitur Flow yang merupakan fitur utama dari NodeRed ini.

\section{Daftar Pustaka}

Setiawan, Dean. SISTEM KENDALI SUHU UDARA DAN KELEMBABAN TANAH PADA

MINIATUR GREEN HOUSE DENGAN MENGGUNAKAN MIKROKONTROLER ATMEGA 328

Nurhayati. (2016). PEMANFAATAN CITRA DIGITAL MULTISPEKTRAL LANDSAT TM UNTUK IDENTIFIKASI KARAKTERISTIK PANTULAN SPEKTRAL KELEMBABAN TANAH PERMUKAAN Studi Kasus : Sebagian Kabupaten Klaten. 
Hardianto, Dena. (2017) PURWARUPA SISTEM SMART HIDROPONIK SEBAGAI PENUNJANG KEGIATAN PRAKTIKUM BERBASIS INTERNET OF THINGS (STUDI KASUS DI SMK PERTANIAN PEMBANGUNAN NEGERI LEMBANG)

Sadiyoko, Ali. PENERAPAN SISTEM MONITORING RUMAH KACA BERBASIS MIKROKONTROLER DI DESA TUGU MUKTI, CISARUA, BANDUNG BARAT 